\title{
Inhibition of Persistent Sodium Current Fraction and Voltage-gated L-type Calcium Current by Propofol in Cortical Neurons: Implications for Its Antiepileptic Activity
}

\author{
*Giuseppina Martella, †Cristiano De Persis, †Paola Bonsi, $\ddagger$ Silvia Natoli, ${ }^{*}$ Dario Cuomo, \\ $* \dagger$ Giorgio Bernardi, †£Paolo Calabresi, and *†Antonio Pisani \\ *Clinica Neurologica, Dipartimento di Neuroscienze, Università di Roma "Tor Vergata”; †Fondazione Santa Lucia, I.R.C.C.S.; \\ ‡Istituto di Anestesia e Rianimazione, Università di Roma “Tor Vergata," Rome, Italy; and \$Clinica Neurologica, Università di \\ Perugia, Perugia, Italy
}

Summary: Purpose: Although it is widely used in clinical practice, the mechanisms of action of 2,6-di-isopropylphenol (propofol) are not completely understood. We examined the electrophysiologic effects of propofol on an in vitro model of epileptic activity obtained from a slice preparation.

Methods: The effects of propofol were tested both on membrane properties and on epileptiform events consisting of longlasting, paroxysmal depolarization shifts (PDSs) induced by reducing the magnesium concentration from the solution and by adding bicuculline and 4-aminopyridine. These results were integrated with a patch-clamp analysis of $\mathrm{Na}^{+}$and high-voltage activated (HVA) calcium $\left(\mathrm{Ca}^{2+}\right)$ currents from isolated cortical neurons.

Results: In bicuculline, to avoid any interference by $\gamma$ aminobutyric acid (GABA)-A receptors, propofol (3-100 $\mu M$ ) did not cause significant changes in the current-evoked, sodium $\left(\mathrm{Na}^{+}\right)$-dependent action-potential discharge. However, propofol reduced both the duration and the number of spikes of PDSs recorded from cortical neurons. Interestingly, relatively low concentrations of propofol [half-maximal inhibitory concentration $\left.\left(\mathrm{IC}_{50}\right), 3.9 \mu \mathrm{M}\right)$ consistently inhibited the "persistent" fraction of $\mathrm{Na}^{+}$currents, whereas even high doses $(\leq 300 \mu M)$ had negligible effects on the "fast" component of $\mathrm{Na}^{+}$currents. HVA $\mathrm{Ca}^{2+}$ currents were significantly reduced by propofol, and the pharmacologic analysis of this effect showed that propofol selectively reduced L-type $\mathrm{HVA} \mathrm{Ca}{ }^{2+}$ currents, without affecting $\mathrm{N}$ or P/Q-type channels.

Conclusions: These results suggest that propofol modulates neuronal excitability by selectively suppressing persistent $\mathrm{Na}^{+}$ currents and L-type $\mathrm{HVA} \mathrm{Ca}^{2+}$ conductances in cortical neurons. These effects might cooperate with the opening of GABA-Agated chloride channels, to achieve depression of cortical activity during both anesthesia and status epilepticus. Key Words: Cortex-Antiepileptic drugs-Paroxysmal depolarizing shiftHVA calcium current-Persistent sodium current.
Growing experimental evidence suggests that antiepileptic drugs (AEDs) and anesthetics may share common mechanisms of action $(1,2)$. Overall, modulation of neuronal activity by both these classes of drugs results from depression of excitatory transmission and enhancement of inhibitory neurotransmission. Indeed, prolongation of $\gamma$-aminobutyric acid (GABA)-A receptor function at GABAergic synapses is thought to be a crucial component of the mechanism of action of many anesthetic drugs, as well as of AEDs. Moreover, the molecular targets for many of the drugs belonging to both categories include the modulation of membrane ion channel function. In particular, compelling evidence has

Accepted November 16, 2004

Address correspondence and reprint requests to Dr. A. Pisani at Clinica Neurologica, Dipartimento di Neuroscienze, Università di Roma "Tor Vergata," Via Montpellier 1, 00133 Rome, Italy. E-mail: pisani@uniroma2.it demonstrated that sodium $\left(\mathrm{Na}^{+}\right)$current inhibition plays a primary role in the mechanism of action both of many AEDs and of anesthetic agents (3-7). More recently, much interest has been focused on the persistent fraction of $\mathrm{Na}^{+}$current $\left(\mathrm{INa}^{+} p\right)$, as several AEDs have been shown selectively to modulate this current (8-11). In addition, high-voltage-activated (HVA) calcium $\left(\mathrm{Ca}^{2+}\right)$ currents are thought to represent a primary source of intracellular $\mathrm{Ca}^{2+}$ during epileptiform activity (12-14), being involved in both seizure generation and propagation. Similar to $\mathrm{Na}^{+}$currents, HVA Ca ${ }^{2+}$ conductances have been shown to be an important target of some anesthetic drugs $(6,7)$. A significant overlap also exists in the clinical effects, because many anesthetic drugs possess antiepileptic activity (15), whereas common AEDs have sedative actions (7).

Propofol, an intravenous anesthetic, is structurally not related to other anesthetic drugs. Its extensive clinical use 
has been justified by the early onset and rapid clearance of the effect, and, conversely, by the lack of significant side effects (16). More recently, propofol has been reported as a successful treatment for refractory status epilepticus $(17,18)$. Several cellular mechanisms of action have been proposed for propofol. Electrophysiologic studies demonstrated that propofol activates both phasic and tonic GABA-A receptor-dependent conductances (19-21). The enhancement of GABA-A-receptor transmission probably accounts for a large portion of its therapeutic efficacy. In addition, the modulation exerted by propofol on neuronal intrinsic excitability has been shown to depend, at least to some extent, on an inhibitory action on $\mathrm{Na}^{+}, \mathrm{Ca}^{2+}$, potassium channels $(2,22)$. To what extent each of these effects contributes to the efficacy of propofol still remains to be determined. This may be partially due to differences in laboratory investigations, but a crucial determinant is represented by the distinct region-specific and cell-typespecific assembly both of ion-channel and transmitterreceptor subunits. Previous studies have shown that neurons in layer $\mathrm{V}$ are necessary for the organization of cortical synchronization; consistently, more recently it has been shown that layer $\mathrm{V}$ neurons play a central role in generating cortical seizures $(12,23)$.

Intracellular recordings from single neurons performed either in pharmacologically induced epileptic foci or in human tissue from epilepsy patients have shown the existence of epileptiform events, consisting of rhythmic membrane depolarizations of large amplitude, known as paroxysmal depolarization shifts (PDSs), generating repetitive, long-lasting bursts of action potentials (24). These epileptiform events have been definitely considered a reliable cellular correlate of the electrical abnormalities observed during electroencephalographic recordings $(13,25)$. Thus we used an intact preparation such as a slice preparation, which ensures that both the circuitry and the native receptor-subunit composition is preserved and physiologically expressed. In this experimental condition, we analyzed the effects of propofol, by means of conventional sharp microelectrode recordings both on intrinsic membrane properties and on pharmacologically induced PDSs in pyramidal neurons from cortical slices. In addition, whole-cell patch-clamp recordings from acutely isolated pyramidal cells were performed to integrate and identify the molecular target of the actions of propofol.

\section{METHODS}

\section{Neocortical slice preparation}

Slices were prepared from Wistar rats, 3-4 weeks of age, as described previously $(4,14,26,27)$, in accordance with European Communities Council Directive (86/609/EEC). Rats were killed under ether anesthesia by cervical dislocation; the brain was rapidly removed, and coronal slices $(200 \mu \mathrm{m}$ thick) from frontal cortex were cut from tissue blocks with a vibratome, in an ice-cold $\left(0^{\circ} \mathrm{C}\right)$ Krebs' solution (see composition later). Then a single slice was placed into a recording chamber mounted on the stage of an upright microscope (Olympus BX50WI), equipped with a $\times 60$ water-immersion objective (LUMPlan FI; Olympus) and submerged in a continuously flowing Krebs' solution gassed with $95 \% \mathrm{O}_{2} / 5 \% \mathrm{CO}_{2}$. In the chamber, temperature was maintained at $32^{\circ} \mathrm{C}$ to $33^{\circ} \mathrm{C}$, and flow rate was $2.5-3.0 \mathrm{ml} / \mathrm{min}$. The composition of the Krebs' solution was (in $\mathrm{mM}$ ): $126 \mathrm{NaCl}, 2.5 \mathrm{KCl}$, $1.3 \mathrm{MgCl}_{2}, 1.2 \mathrm{NaH}_{2} \mathrm{PO}_{4}, 2.4 \mathrm{CaCl}_{2}, 10$ glucose, 18 $\mathrm{NaHCO}_{3}$.

\section{Electrophysiology from brain slices}

Intracellular recordings from pyramidal cells were obtained from layer $\mathrm{V}$ of the frontal cortex, visualized on the surface of the slice by using a differential interference contrast (DIC, Nomarski) optical system combined with an infrared (IR) filter, a monochrome CCD camera (COHU 4912, Cohu, Inc., San Diego, CA, U.S.A.), displayed on a PC monitor. Sharp microelectrodes were filled with a $2 \mathrm{M} \mathrm{KCl}$ solution. However, to avoid interference by chloride ions, most of the experiments were performed with a $2 M \mathrm{~K}$-acetate solution in the recording pipette, yielding a resistance of $\sim 45-55$ MOhms. An Axoclamp 2B amplifier was used for conventional microelectrode recordings from brain slices. Traces were displayed on an oscilloscope (Gould Classic 6000), stored both on a highgain chart recorder (Gould RS 3400) and on AxoScope 9.0 (Axon Instruments Union City, CA, U.S.A.) running on a PC. Off-line analysis was performed with pClamp 9 (Clampfit; Axon Instruments). The drugs were dissolved to the final concentration in the saline and bath-applied after a three-way tap had been turned on. Values given in the text and in the figures are expressed as percentage of control and represent the mean \pm SEM of changes in the respective cell populations. Student's $t$ test (for paired and unpaired observations) was used to compare the means.

\section{Preparation of acutely dissociated neurons}

Slices from frontal cortex were incubated in Hepesbuffered Hank's balanced salt solution (HBSS), bubbled with pure oxygen. Temperature was kept at $35^{\circ} \mathrm{C}$. Then deep cortical layers were dissected from a neocortical slice and incubated in HBSS medium containing $0.5 \mathrm{mg} / \mathrm{ml}$ protease XIV. After $30 \mathrm{~min}$, the tissue was repeatedly washed in HBSS and mechanically dissociated by triturating with a series of progressively smaller fire-polished Pasteur pipettes. The resultant cell suspension was then placed in a Petri dish positioned on the stage of an inverted microscope (Nikon Diaphot; Japan). Healthy cells were allowed to settle for $\sim 10 \mathrm{~min}$. Only presumed pyramidal neurons were chosen for recordings.

\section{Whole-cell patch-clamp recordings}

Pyramidal neurons were identified by their peculiar shape and by the typical apical process spared by the enzymatic dissociation (Fig. 4A). Patch-clamp recordings 
in the whole-cell configuration were performed by using fire-polished pipettes (WPI PG52165-4) pulled on a Sutter Flaming-Brown micropipette puller (Sutter Instruments, Novato, CA, U.S.A.). Pipette resistance ranged between 6 and $9 \mathrm{MOhms}$. Extracellular and dialyzing solutions were prepared to separate $\mathrm{Na}^{+}$and $\mathrm{Ca}^{2+}$ currents effectively. When either the fast $(f)$ or the persistent $(p)$ fractions of $\mathrm{Na}^{+}$currents $\left(\mathrm{INa}^{+}\right)$were investigated, cortical neurons were dialyzed with an internal solution containing (in mM): $N$-methyl-D-glucamine 185, HEPES 40, EGTA $11, \mathrm{MgCl}_{2} 4, \mathrm{CaCl}_{2} 0.2$, and, finally added in the dailyarranged working solution, phosphocreatine 20, ATP 2-3, GTP $0-0.2$, leupeptin 0.2 ; the osmolarity was $264-270$ $\mathrm{mOsm} / \mathrm{L} ; \mathrm{pH}$ was adjusted to 7.3 with phosphoric acid. The external solution for $\mathrm{INa}^{+} f$ consisted of (in $\mathrm{m} M$ ): TEA-Cl 100, HEPES 10, $\mathrm{BaCl}_{2} 5, \mathrm{MgCl}_{2} 1, \mathrm{CsCl} 5, \mathrm{NaCl}$ $40, \mathrm{KCl} 5, \mathrm{CdCl}_{2}$ 0.4; $\mathrm{pH}$ was adjusted to 7.4 with $\mathrm{NaOH}$. $\mathrm{INa}^{+} p$ was recorded in the presence of an external solution containing (in mM): TEA-Cl 30, HEPES $10, \mathrm{BaCl}_{2}$ $5, \mathrm{MgCl}_{2} 1.5, \mathrm{NaCl} 115, \mathrm{KCl} 2.5, \mathrm{CdCl}_{2}$ 0.4; the osmolarity was $297-300 \mathrm{mOsm} / \mathrm{L}$; $\mathrm{pH}$ was adjusted to 7.4 with $\mathrm{NaOH}$.

Conversely, when HVA $\mathrm{Ca}^{2+}$ currents were examined, the composition of the internal solution was (in $\mathrm{mM}$ ): Nmethyl-D-glucamine 185, HEPES 40, EGTA $11, \mathrm{MgCl}_{2}$ 4 , and, finally added to the daily-arranged working solution, phosphocreatine 20, ATP 2-3, GTP $0-0.2$, and leupeptin 0.2 ; the osmolarity was $275-280 \mathrm{mOsm} / \mathrm{L}$. After obtaining the cell access, the neuron was usually bathed in a medium composed of (in mM): TEA-Cl 165, HEPES $10, \mathrm{CsCl} 5$, and $\mathrm{BaCl}_{2} 5$ as the charge carrier; $\mathrm{pH}$ was adjusted to 7.35 , and the osmolarity, to $\sim 300 \mathrm{mOsm} / \mathrm{L}$. Recordings were made with an Axopatch 1D (Axon Instruments, U.S.A.) at room temperature. Series resistance compensation was routinely used $(70-80 \%)$. Data were low-pass filtered (corner frequency, $5 \mathrm{KHz}$ ). For data acquisition and analysis, pClamp 8 running on $\mathrm{PC}$ was used. Barium currents were studied with both voltage steps and ramps $(0.3-0.6 \mathrm{mV} / \mathrm{ms})$. Control and drug solutions were applied with a linear array of six, gravity-fed capillaries positioned within $500-600 \mu \mathrm{m}$ of the patched neuron. The $\mathrm{pH}$ of the solutions was checked before perfusion.

Data analysis was performed off-line by using Microcal Origin and Graphpad Prism softwares running on PC. Values given in the text and in the figures are mean \pm SEM of changes in the respective cell populations. The evaluation of statistical difference was performed with two-way analysis of variance (ANOVA) test.

\section{Drug source and handling}

Nimodipine, $\omega$-conotoxin GVIA, $\omega$-conotoxin MVIIC, and $\omega$-agatoxin IVA were from Alomone Labs (Israel). Lamotrigine (LTG) was kindly provided by Glaxo-SmithKline (U.K.). Propofol and all other compounds were purchased from Sigma (Italy).

\section{RESULTS}

\section{Characterization of the neurons recorded from slices}

Conventional electrophysiological recordings in the current-clamp mode were performed from 57 pyramidal neurons from layer $\mathrm{V}$ of the frontal neocortex, visually identified by means of a standard IR-DIC system on the slice surface (Fig. 1A). Layer borders were assessed by the visualization of a thin layer of large pyramidal neurons, to determine layer $\mathrm{V}$, and by the distance from the pial surface of the slice. Electrophysiologic properties of cortical neurons have been described in detail previously $(28,29)$. Distinct neuronal subtypes can be recognized according to their electrical behavior (30-34). The recorded neurons had a mean resting membrane potential (RMP) of -71 $\pm 2 \mathrm{mV}$. The injection of hyperpolarizing current in the recorded cell evoked a typical hyperpolarization-activated inward current, or $\mathrm{I}_{\mathrm{h}}$ (Fig. 1B). In the present work, to render homogeneous the neuronal population, we chose to include only neurons that, on depolarizing current pulses, evoked a sustained action-potential discharge. Cells with an RMP more negative than $-65 \mathrm{mV}$ and action potentials

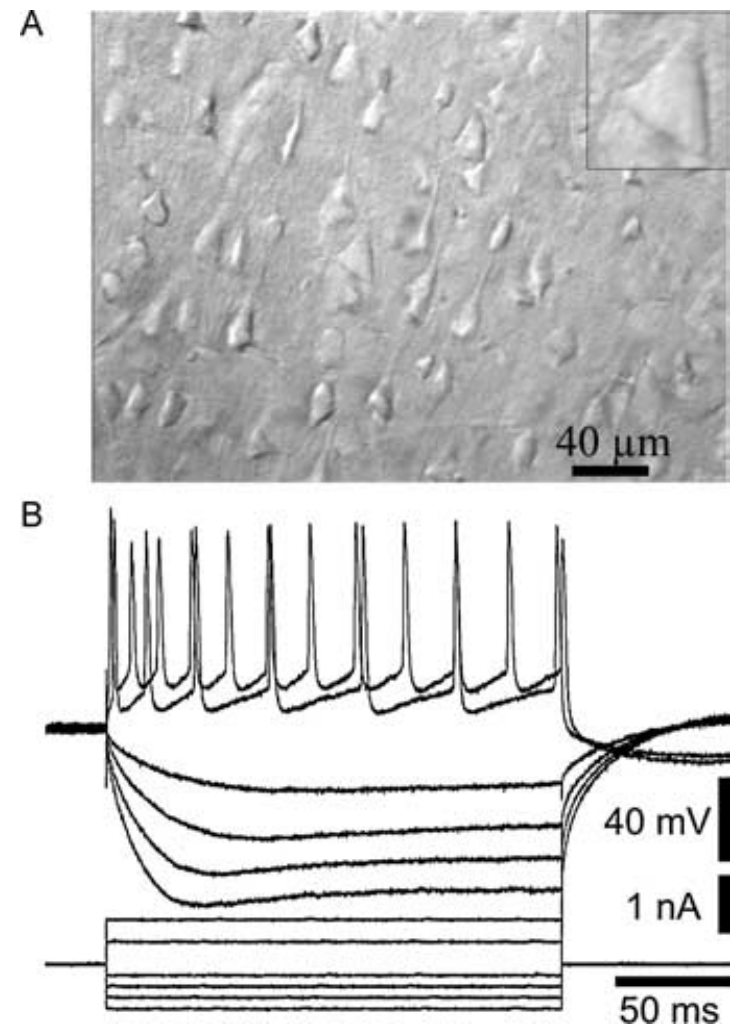

FIG. 1. Morphologic and electrophysiologic properties of cortical pyramidal neurons. A: IR-DIC image of a cortical coronal slice. Bar, $40 \mu \mathrm{m}$. A pyramidal cortical neuron is shown at higher magnification in the inset. B: Membrane potential response to current injections in a cortical pyramidal neuron. Depolarizing current pulses (0.4-0.8 nA, $200 \mathrm{~ms}$ ) evoked a sustained firing activity, followed by an afterhyperpolarization. Hyperpolarizing current pulses of increasing amplitude $(0.6-0.8 \mathrm{nA}, 200 \mathrm{~ms})$ evoked a typical $\mathrm{l}_{\mathrm{h}}$ current. Resting membrane potential (RMP), $-73 \mathrm{mV}$. 
A

a control

b in propofol
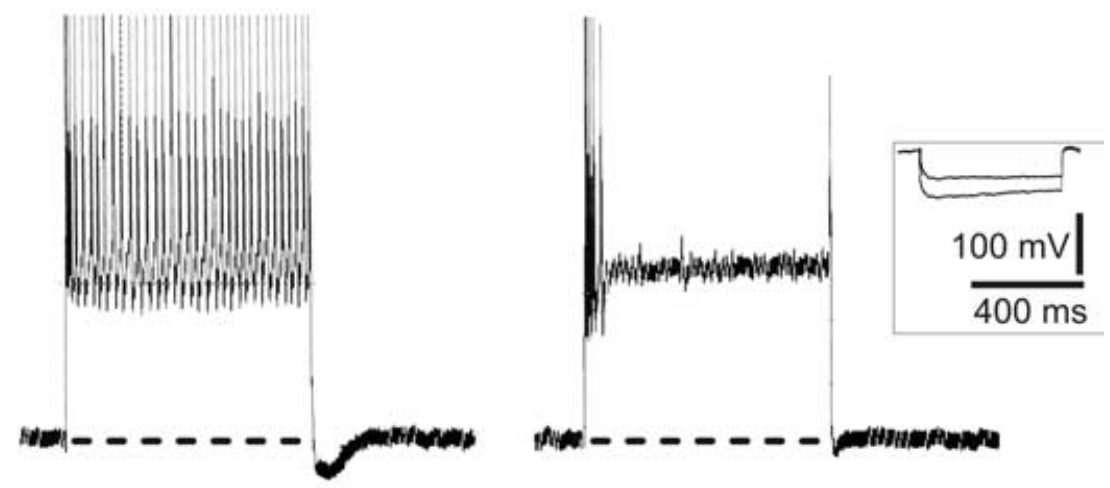

FIG. 2. $\gamma$-Aminobutyric acid (GABA)-Areceptor blockade prevents the effects of propofol on action-potential discharge. A: Injection of a depolarizing current pulse (0.9 $\mathrm{nA}, 1 \mathrm{~s}$ ) evoked a sustained action-potential discharge in a pyramidal neuron (a) (resting membrane potential, RMP, $-70 \mathrm{mV}$ ). Bathapplication of a low dose of propofol $(3 \mu M)$ abolished the firing activity (b). A significant decrease in the input resistance of the recorded cell, measured by means of hyperpolarizing current steps $(0.8 \mathrm{nA}, 400 \mathrm{~ms})$ was observed in propofol (inset). B: In another recording, performed in the presence of bicuculline (BIC; $30 \mu M$ ) and with K-acetate in the recording microelectrode, propofol $(100 \mu M)$ was unable to affect either the current-induced firing activity $(0.9 \mathrm{nA}, 1 \mathrm{~s})$ or the input resistance of the recorded neuron (b, inset). Note that the top of spikes has been truncated.
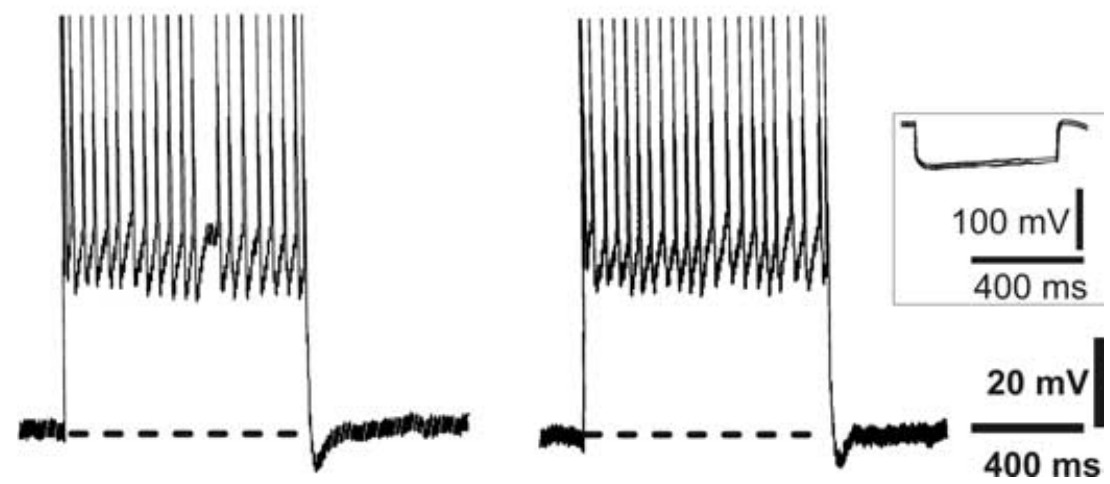

antagonist bicuculline in the perfusing solution $(30 \mu M)$ and with $\mathrm{K}$-acetate in the recording electrode (Fig. 2B). Effectively, in these conditions, even higher doses of propofol $(10-100 \mu M)$ failed to affect $\mathrm{Na}^{+}$-dependent action-potential discharge (Fig. 2Bb; $\mathrm{n}=11 ; \mathrm{p}>0.05$ ), suggesting that the abrupt cessation of firing discharge observed in the former group of experiments was due to a membrane shunt secondary to the opening of GABAA-dependent chloride channels (35). Accordingly, in the presence of bicuculline, membrane resistance was unchanged, as measured at the steady state of hyperpolarizing current steps (Fig. 2B, inset).

\section{Propofol effect on epileptiform activity}

The apparent lack of effect of propofol on $\mathrm{Na}^{+}$dependent firing activity prompted us to search for an effect in another experimental condition (i.e., the pharmacologic induction of epileptiform events). Incubation of the slices in a magnesium-free solution containing 4-aminopyridine (4-AP, $500 \mu M$ ) and bicuculline (BIC, $30 \mu M$ ) resulted in the induction of spontaneous epileptiform events, named PDSs. This experimental condition allows removal of the magnesium-dependent block 
A
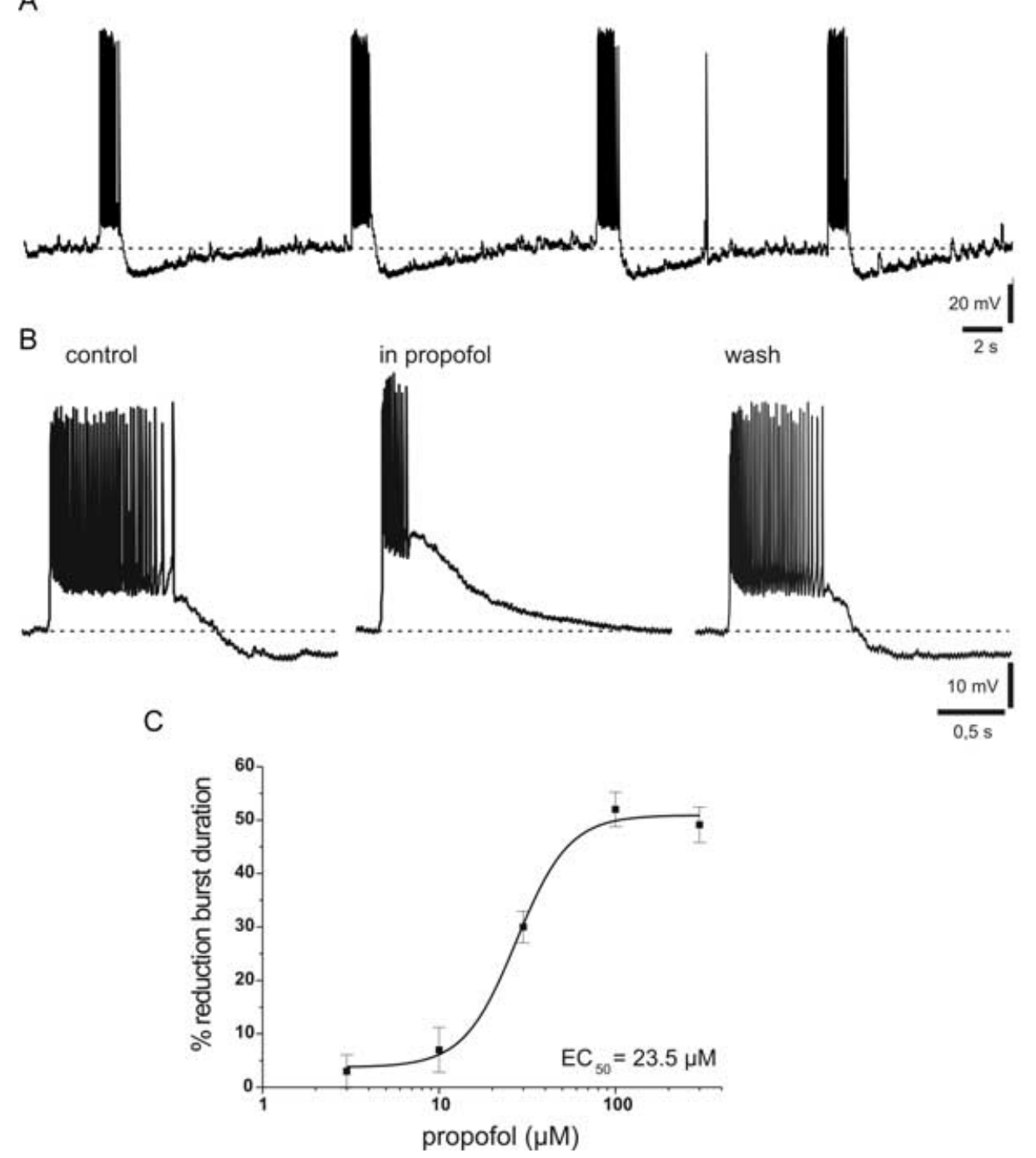

FIG. 3. Propofol inhibits cortical epileptiform activity. A: Perfusion of the slice with a solution containing low-magnesium, $30 \mu M$ bicuculline (BIC) and 0.5 mM 4-aminopyridine (4-AP; 15-20 min) caused the appearance of epileptiform activity in pyramidal neurons, characterized by periodic, long-lasting bursts and by occasional interictal activity. Each burst was followed by a pronounced after-hyperpolarization. Resting membrane potential (RMP), $-71 \mathrm{mV}$. B: Incubation of the slice with $100 \mu \mathrm{M}$ propofol (10-20 min) caused a marked reduction of the burst duration. Duration was measured from the onset of firing activity to the half-decay time of repolarization. The number of spikes per burst was reduced. The amplitude of the after-hyperpolarization was largely reduced as well. Both duration and number of spikes of paroxysmal depolarization shifts (PDSs) were partially restored to control conditions after a long washout ( $\sim 40 \mathrm{~min})$ of propofol. RMP, $-68 \mathrm{mV}$. C: Dose-response curve for the inhibitory effect of propofol on epileptiform events. Each point represents the mean of at least four independent observations.

of NMDA glutamate receptors, blocking of potassium channels, and antagonizing of GABA-A receptors, respectively. Twenty minutes after the onset of bath-application of the slice with this solution, spontaneous PDSs were recorded (Fig. 3A and B; $n=37$ ), consisting of large shifts of membrane potential in the depolarizing direction (12 $\pm 1.2 \mathrm{mV}$ amplitude). PDSs had a mean frequency close to $0.1 \mathrm{~Hz}$ and triggered long-lasting $(1.4 \pm 0.2 \mathrm{~s})$ bursts of action potentials, followed by a marked afterhyperpolarization (AHP). Expectedly, tetrodotoxin (TTX, $1 \mu M$ ) fully suppressed the PDSs ( $\mathrm{n}=3$, not shown). Likewise, PDSs were fully blocked by 100-200 $\mu M$ cadmium, demonstrating the close dependence of PDS on $\mathrm{Ca}^{2+}$ influx ( $\mathrm{n}=4$, not shown).

Perfusion of the slices with propofol (3-300 $\mu M)$ significantly decreased the duration of PDSs (Fig. 3B). Duration was measured from the onset of spike discharge to the half-decay time of the repolarizing phase. No significant change of the PDS frequency rate was observed (not shown). These effects were dose dependent, with a maximal inhibition obtained at $100 \mu M$ (Fig. 3C; $\mathrm{n}=24$; $\mathrm{p}<$ 0.001 ), and with a half-maximal effective dose $\left(\mathrm{EC}_{50}\right)$ for the inhibitory effect of $23.54 \mu M$. The effect of propofol was paralleled by a decreased number of action potentials 
inscribed on each burst (Fig. 3B). In $100 \mu M$ propofol, the number of spikes per burst was decreased by $45 \pm 7.1 \%$ $(p<0.01)$. Finally, the pronounced AHP after each PDS was largely reduced by bath-applied propofol (Fig. 3B). A long drug washout was necessary (20-40 min) to allow a partial recovery of PDS duration.

\section{Selective inhibitory action of propofol on $\mathrm{INa}^{+} \mathrm{p}$}

Fifty-five pyramidal neurons were acutely isolated from layer $\mathrm{V}$ of frontal cortex. The typical pyramidal shape with one main apical dendrite allowed their unequivocal identification (Fig. 4A). Both fast inactivating $\left(\mathrm{INa}^{+} f\right)$ and slowly inactivating/persistent $\mathrm{INa}^{+}\left(\mathrm{INa}^{+} p\right)$ could be evoked in these neurons (Fig. 4B). Total $\mathrm{INa}^{+}$was evoked by means of depolarizing ramp potentials (from -70 to $+30 \mathrm{mV}$ ); both current fractions were sensitive

\section{A}

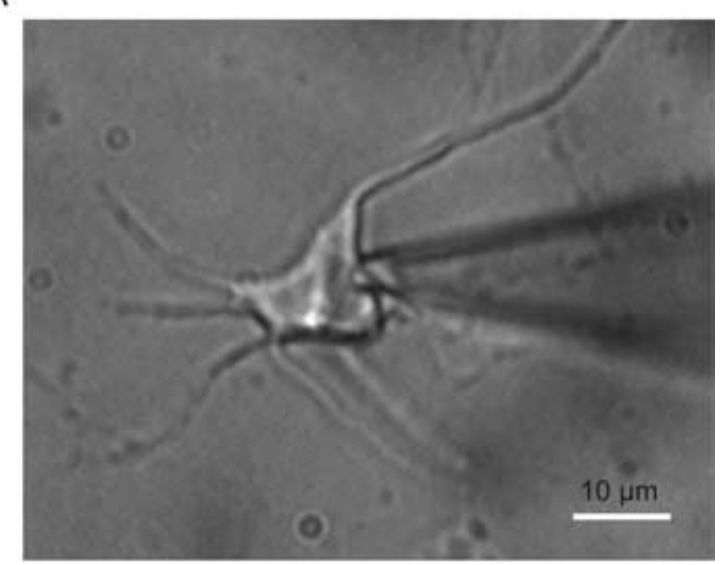

B
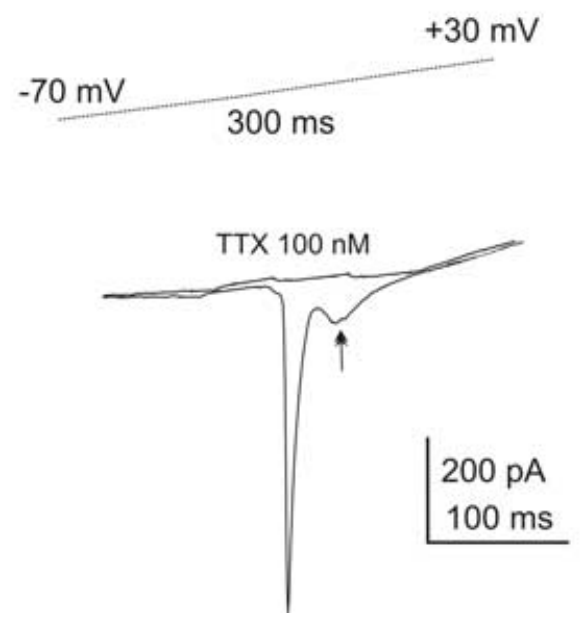

FIG. 4. Morphologic and electrophysiologic features of the recorded neurons. A: Photomicrograph of an acutely dissociated pyramidal neuron. Note the major apical process spared by the dissociation procedure (bar, $10 \mu \mathrm{m}$; magnification, $\times 40)$. B: The trace shows the total $\mathrm{Na}^{+}$current, evoked by a ramp protocol ranging from -70 to $+30 \mathrm{mV}$, and characterized by the presence of both the $\mathrm{INa}^{+} f$ and $\mathrm{INa}^{+} p$ fractions (the latter indicated by the arrow). Superimposed is the full suppression of both components by $100 \mathrm{nM}$ tetrodotoxin (TTX). to TTX (100 nM, Fig. 4B). All the recorded cells exhibited a prominent $\mathrm{INa}^{+} p$, which was evoked by ramping membrane voltage from $-70 \mathrm{mV}$ to $+15 \mathrm{mV}(25 \mathrm{mV} / \mathrm{s})$, slowly enough to avoid transient $\mathrm{Na}^{+}$channel opening and consistently capable of evoking the small, persistent, TTX-sensitive $\mathrm{INa}^{+} p$ (Fig. 5A). In agreement with previous findings in cortical neurons $(36,37), \mathrm{INa}^{+} p$ begins to activate between -65 and $-55 \mathrm{mV}$, with a peak around $-35 /-40 \mathrm{mV}$ (not shown). Propofol was bath-applied in a solution containing both BIC $(30 \mu M)$ and 5-nitro 2-(3-phenylpropylamine) benzoic acid (NPPB; $10 \mu M$ ), a mixed blocker of volume-activated and $\mathrm{Ca}^{2+}$-activated chloride channels. In this experimental condition, low concentrations of propofol were able reversibly to suppress the peak amplitude of $\mathrm{INa}^{+} p$ (Fig. 5A). This inhibition was dose dependent, with an $\mathrm{IC}_{50}$ of $3.9 \mu M$ (Fig. 5B), a maximal inhibition at $30 \mu M$, and a calculated Hill coefficient of $1.3 \pm 0.3$.

The effects of propofol were then tested on $\mathrm{INa}^{+} f$ evoked by current steps ranging from the holding potential $(-70 \mathrm{mV})$ to $-20 \mathrm{mV}$ (Fig. 5C). This set of experiments was performed in a low- $\mathrm{Na}^{+}-$containing solution (see Methods for details), added with BIC and NPPB (30 and $10 \mu M$, respectively). Propofol, at all the doses tested $(0.1-300 \mu M)$ failed to affect $\mathrm{INa}^{+} f$ (Fig. $5 \mathrm{C}$ and D; $\mathrm{n}=15 ; \mathrm{p}>0.05)$. No change in current activation was observed during the control experiments, in which the neurons were perfused with dimethylsulfoxide (DMSO) at the same concentration as that used to dissolve propofol (not shown; $\mathrm{n}=3$ ).

\section{Comparative study with valproic acid}

To compare the effects of propofol with a wellestablished AED, another set of experiments was performed with valproic acid (VPA). This drug is known selectively to affect the persistent fraction of $\mathrm{INa}^{+}$(9). Indeed, the addition of VPA $(100 \mu M)$ to the perfusing solution had no effect on $\mathrm{INa}^{+} f$ amplitude, whereas it significantly reduced $\mathrm{INa}^{+} p$ (Fig. 6A and $\mathrm{B} ; \mathrm{n}=6 ; \mathrm{p}<0.01$ ). The effect of VPA on PDS was then analyzed. VPA (200 $\mu M, 30 \mathrm{~min}$ ) was able to reduce by $56.8 \pm 1.8 \%$ the number of action potentials inscribed on each PDS (Fig. 6C; $\mathrm{n}=5 ; \mathrm{p}<0.01)$ without significantly affecting the duration of PDS (Fig. 6C; $5.5 \pm 4.3 \%$ inhibition; $p>0.05$ ).

\section{Blockade of L-type $\mathrm{HVA} \mathrm{Ca}^{2+}$ channels}

With barium as the charge carrier, HVA $\mathrm{Ca}^{2+}$ currents were isolated from 38 pyramidal cells. From a negative holding potential $(-90 \mathrm{mV}), \mathrm{HVA}$ currents were activated by standard test-pulses (from -10 to $+10 \mathrm{mV}$ ) or ramp activation protocol ranging from -70 to $+40 \mathrm{mV}$. All the experiments were performed in the presence of BIC $(30 \mu M)$ and NPPB $(10 \mu M)$ in the bathing solution. Propofol (1-300 $\mu M)$, dose dependently reduced barium currents in all the recorded neurons (Fig. 7). The maximal inhibition was obtained at a concentration of $100 \mu M$ 
A
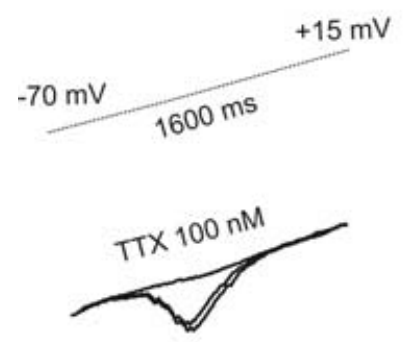

control $=$ wash $250 \mathrm{pA}$
$400 \mathrm{~ms}$
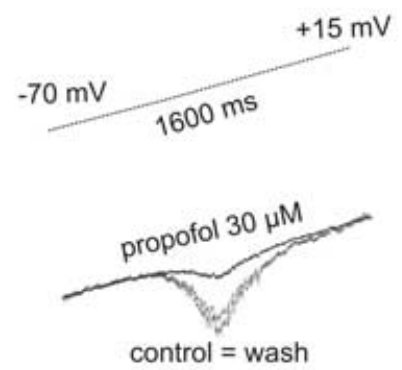

$250 \mathrm{pA}$
$400 \mathrm{~ms}$

C

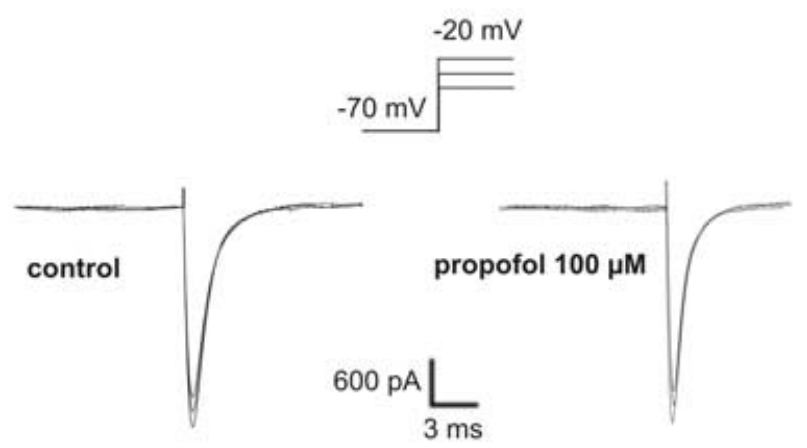

B

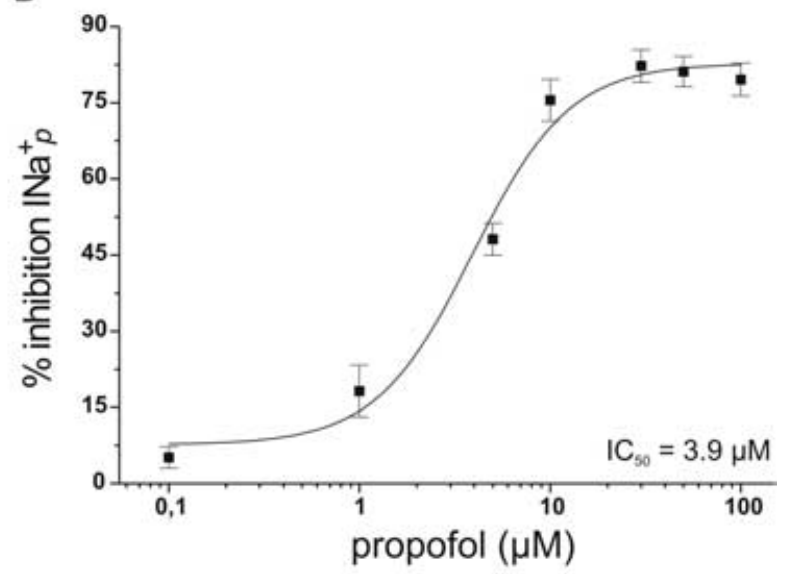

D

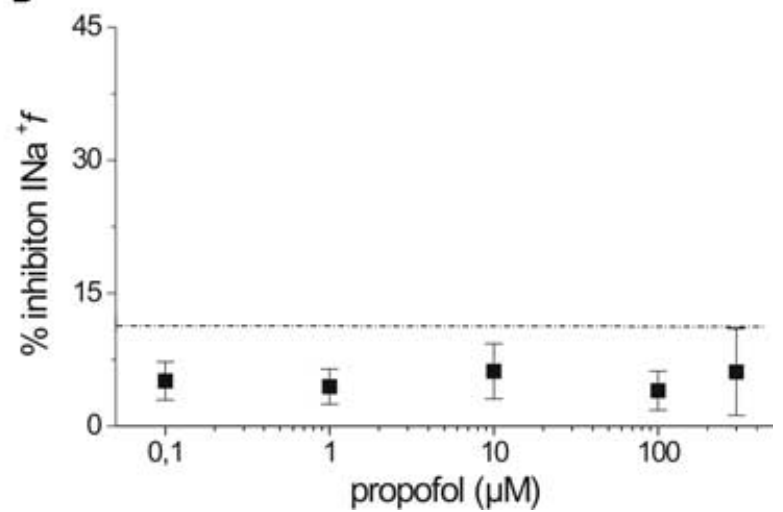

FIG. 5. Effects of propofol on $I \mathrm{Na}^{+} f$ and $I \mathrm{Na}^{+} p$ fractions. A: INa ${ }^{+} p$ evoked by a slow ramp voltage protocol (from -70 to $+15 \mathrm{mV}$ in a time window of $1,600 \mathrm{~ms}$, left trace). The superimposed trace shows the sensitivity of INa ${ }^{+} p$ to tetrodotoxin (TTX). The right traces show $\mathrm{INa}^{+} p$ obtained under control conditions, in the presence of propofol $(30 \mu \mathrm{M})$, and after drug washout. B: Dose-response curve for the inhibitory effect of propofol on $\mathrm{INa}^{+} p$ peak amplitude, with a half-maximal inhibitory concentration $\left(\mathrm{IC}_{50}\right)$ of $3.9 \mu \mathrm{M}$. C: Control INa ${ }^{+} f$ was activated by three test pulses to $-20 \mathrm{mV}$ from a holding potential of $-70 \mathrm{mV}$ (left traces). The right traces show INa ${ }^{+} f$ in the presence of $100 \mu \mathrm{M}$ propofol. D: The curve summarizes the lack of effect of propofol at all the concentrations tested $(0.1-300 \mu \mathrm{M})$. Each point in $\mathbf{B}$ and $\mathbf{D}$ represents the mean of at least six independent observations.

(Fig. 7C; $26 \pm 3.8 \% ; \mathrm{n}=12 ; \mathrm{p}<0.001)$. Determined $\mathrm{IC}_{50}$ for the inhibition by propofol was $23.1 \pm 0.6 \mu \mathrm{M}$. As shown in Fig. 7A and B, the blockade of HVA currents reversed on washout of propofol, independent of the dose tested.

A set of experiments was then performed to discriminate the HVA $\mathrm{Ca}^{2+}$ channel subtype involved in this inhibitory action of propofol. The dihydropyridine blocker nimodipine selectively blocks L-type channels in a concentration range between 5 and $50 \mu M$. Bath-application of $5 \mu \mathrm{M}$ nimodipine reduced the total $\mathrm{Ca}^{2+}$ current activated by step pulses by $23.1 \pm 4 \%$ (Fig. $8 \mathrm{~A}$ and $\mathrm{B} ; \mathrm{n}=8$; $\mathrm{p}<0.001)$. Interestingly, in the presence of nimodipine, the inhibition of saturating doses of propofol $(100 \mu M)$ was occluded (Fig. 8A and B; $\mathrm{n}=8 ; \mathrm{p}>0.05$ ), suggesting that dihydropyridine-sensitive currents play a prominent role in the inhibitory action of propofol on cortical neurons. Conversely, N-, P-, and Q-type HVA currents do not appear to be preferential targets of propofol. Per- fusion with $1 \mu M \omega$-conotoxin GVIA, a peptide known to selectively block N-type HVA channels reduced, per se, the peak amplitude currents by $33.3 \pm 3.4 \%$ (Fig. 8C and $\mathrm{D} ; \mathrm{n}=6 ; \mathrm{p}<0.005)$. However, in the presence of $1 \mu M \omega$-conotoxin GVIA, bath-applied propofol $(100 \mu M)$ was still effective, resulting in a cumulative inhibitory effect (Fig. 8C and D; $54.2 \pm 3.2 \%$; $\mathrm{n}=5 ; \mathrm{p}<0.001)$. Then we analyzed the possible involvement of P- and Q-type HVA channels. Application of the selective blocker of P-type channels, $\omega$-agatoxin IVA $(20 \mathrm{n} M)$, caused a reduction of the total $\mathrm{Ca}^{2+}$ current of $17.1 \pm 4 \%$ (Fig. 8E; $n=5 ; p<0.001$ ). Yet the inhibition caused by propofol was not antagonized (Fig. 8E; $49.1 \pm 2 \% ; \mathrm{n}=5 ; \mathrm{p}<0.005$ ). Likewise, the blockade of Q-type HVA current fraction by $\omega$-conotoxin MVIIC (100 nM; Fig. 8F; $16.8 \pm 3.2 \% ; \mathrm{n}=9 ; \mathrm{p}<0.001)$ did not modify the inhibition by propofol (Fig. $8 \mathrm{~F} ; 41.5 \pm$ $2.3 \% ; \mathrm{n}=8 ; \mathrm{p}<0.005)$. Finally, in four pyramidal neurons, the effect of DMSO was tested, at concentrations 
A

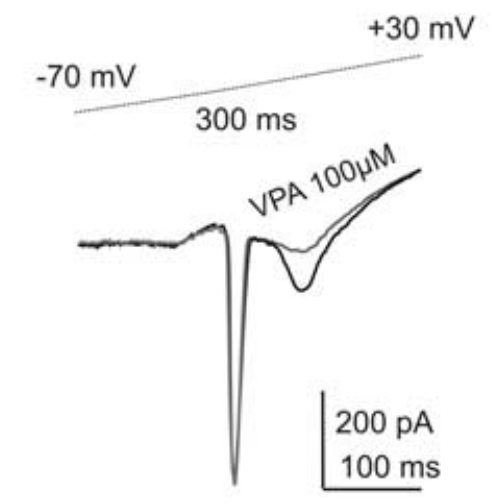

C

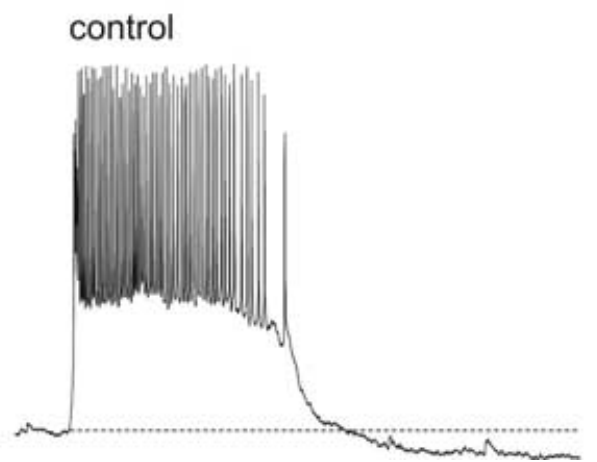

B

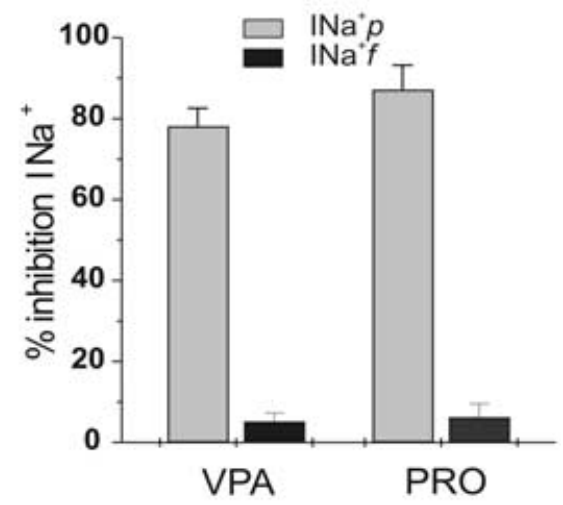

in valproic acid

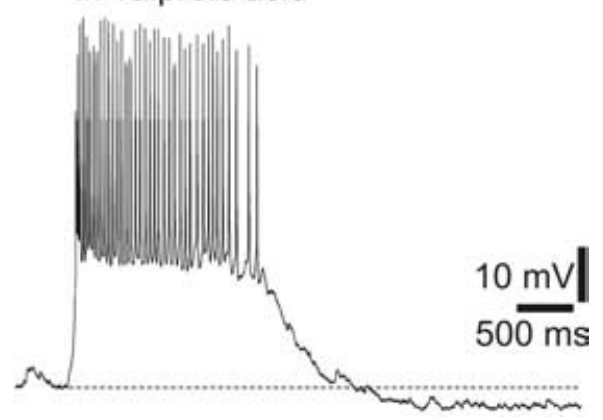

FIG. 6. Comparative effects of valproic acid (VPA). A: The trace shows the total INa ${ }^{+}$in control and in the presence of $100 \mu M$ VPA. Note the lack of effect of VPA on INa+ $f$, whereas the peak amplitude of $\mathrm{INa}^{+} p$ was largely reduced. B: Cumulative plots of the effects of VPA and propofol (PRO) on the peak amplitude of the two distinct components of the total INa+ ${ }^{+}$C: Epileptiform activity was induced in the recorded pyramidal neuron by perfusion of the slice with a solution containing low-magnesium, $30 \mu \mathrm{M}$ bicuculline (BIC) and $0.5 \mathrm{mM}$ 4-aminopyridine (4-AP). After 20 min, incubation of the slice with $200 \mu M$ VPA (20-30 min) caused a marked reduction in the number of spikes per single paroxysmal depolarization shifts (PDS), whereas the burst duration, measured from the onset of firing activity to the half-decay time of repolarization, was unaffected. Resting membrane potential (RMP), $-66 \mathrm{mV}$.

used to dissolve propofol. A vehicle-induced reduction of peak HVA current amplitude was observed $(<10 \%)$, which was subtracted from all the data presented.

\section{DISCUSSION}

Current theories suggest common sites of action for anesthetics and antiepileptic drugs. Despite this evidence, the identification of the molecular targets of these drugs remains, in some aspects, elusive. In the present work, we used conventional recordings to show that propofol effectively reduces both duration and spiking activity of epileptiform events in cortical pyramidal neurons from a slice preparation. The data obtained from whole-cell recordings suggest that such an inhibitory effect might be at least partially ascribed to the selective modulation of both the $\mathrm{INa}^{+} p$ fraction and L-type $\mathrm{HVA} \mathrm{Ca}{ }^{2+}$ currents.

The hallmark of the epileptiform activity is represented by repetitive, persistent depolarization of the neuronal voltage lasting seconds to minutes $(24,25)$. Spontaneous shifts in membrane potential, PDSs, have been shown to occur both in pharmacologically induced epileptic foci and in human tissue from epilepsy patients undergoing surgery. These events have long been considered the cellular correlate of epileptic activity (25). We found that propofol decreases both the number of action potentials per burst and the duration of these events. Interestingly, PDSs were hypothesized to be sustained by $\mathrm{INa}^{+} p(8,38)$. This current fraction is thought to play a central role both in governing the excitability of cortical pyramidal neurons and in the generation of epileptiform activity $(8,36,37)$. Most of the studies of anticonvulsant actions on $\mathrm{Na}^{+}$currents to date have examined the effects of the drugs on the peak $\mathrm{Na}^{+}$current $(39,40)$. However, if a $\mathrm{INa}^{+} p$ is crucial in maintaining ictal depolarization, it may be the most relevant portion of the $\mathrm{Na}^{+}$current to study.

To our knowledge, the present data provide the first experimental evidence of an inhibitory action of an anesthetic drug on $\mathrm{INa}^{+} p$. Notably, this inhibition was obtained at relatively low concentrations of propofol, which confers a certain selectivity to its action. Indeed, it is commonly accepted that low concentrations may selectively target the $\mathrm{INa}^{+} p$ fraction of the total $\mathrm{INa}^{+}$, whereas the 
A

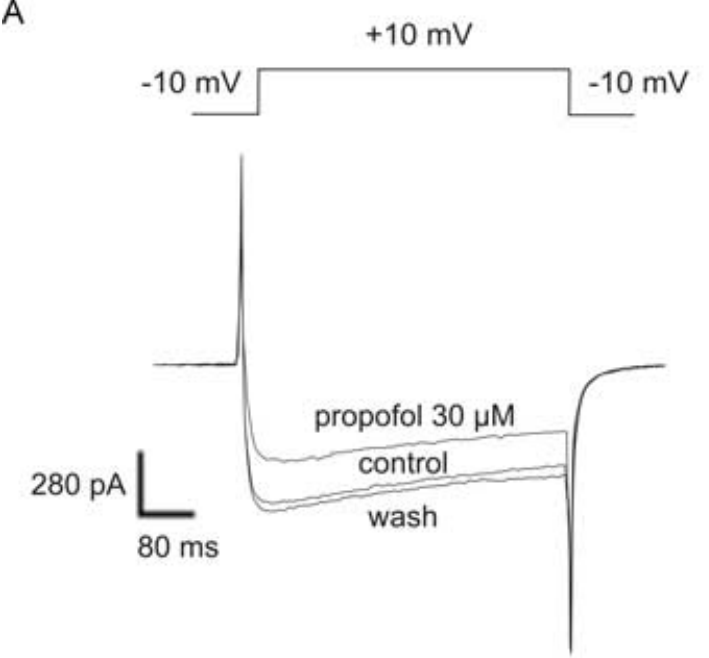

B
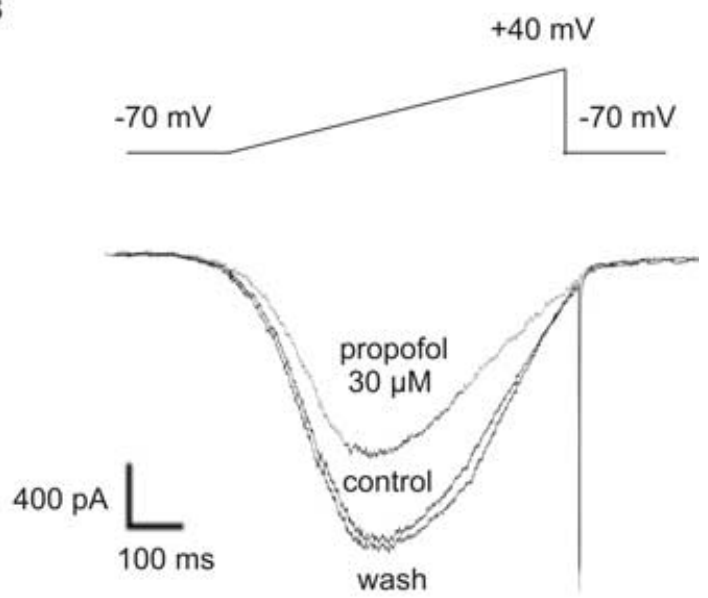

C

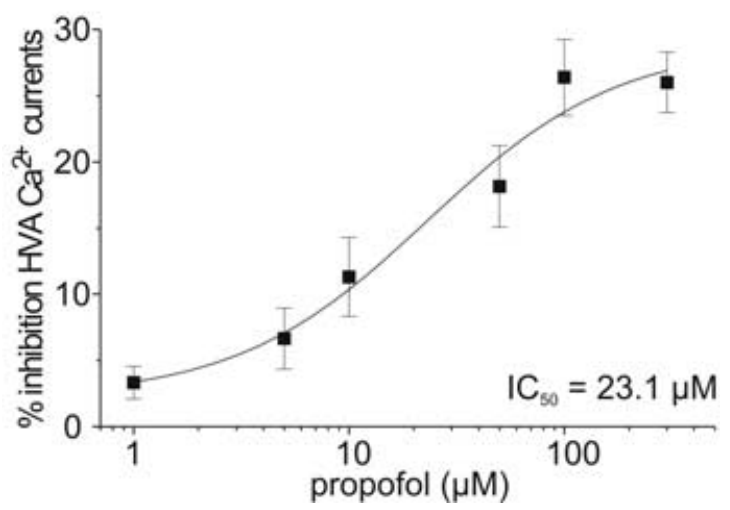

FIG. 7. Inhibitory modulation of high-voltage activated (HVA) $\mathrm{Ca}^{2+}$ currents by propofol. A: HVA Ca ${ }^{2+}$ currents were activated by standard test pulses (from -10 to $+10 \mathrm{mV}$ ). Representative traces showing the HVA $\mathrm{Ca}^{2+}$ current in control conditions and in the presence of $30 \mu \mathrm{M}$ propofol, which reduced the total current amplitude. On washout, the current returned to control levels. B: Voltage ramps ranging from $-70 \mathrm{mV}$ to $+40 \mathrm{mV}$ were applied to activate $\mathrm{Ca}^{2+}$ currents. Application of $30 \mu \mathrm{M}$ propofol consistently depressed the total $\mathrm{Ca}^{2+}$ current. This inhibitory effect was reversible on drug washout. C: Dose-response curve of the propofol-mediated inhibition of HVA currents. Each point of the curve represents the mean \pm SEM of 12 independent observations. higher the dose, the more likely the involvement of $\mathrm{INa}^{+} f$. Instead, even much higher doses of propofol failed to affect $\mathrm{INa}^{+} f$ in cortical neurons. The blockade of $\mathrm{INa}^{+} p$ has been reported for different AEDs, such as phenytoin, VPA, and topiramate $(8-10,41)$. In line with such experimental evidence, our comparative analysis confirmed that VPA selectively targets $\mathrm{INa}^{+} p$, with no effect on $\mathrm{INa}^{+} f$. Moreover, in line with these observations is also the lack of effect of propofol on current-induced action-potential discharge observed in the present study and recently reported in hippocampal interneurons (21). Both in our study and in the latter work, the suppression of action-potential firing was fully prevented by blocking GABA-A receptoroperated chloride conductances. The blockade of $\mathrm{INa}^{+} p$ might also account for the inhibitory effect on the spiking activity inscribed on each PDS, because this current fraction is thought to sustain bursting activity in pyramidal cortical neurons (36). Thus its blockade by propofol might contribute to the overall reduced excitability.

Few electrophysiological studies have analyzed the role of $\mathrm{INa}^{+}$currents in the mechanism of action of propofol. Previously, $\mathrm{INa}^{+}$currents were examined in synaptosomal preparations, with toxin-treated activated $\mathrm{Na}^{+}$channels (42). Recently, propofol, tested on IIa $\mathrm{Na}^{+}$channel $\alpha$ subunits transfected in Chinese hamster ovary cells, was found to suppress total $\mathrm{Na}^{+}$currents both by causing a hyperpolarizing shift of steady-state inactivation and by a use-dependent block of the channel (22). These findings are in apparent contrast with our data supporting a selective action of propofol on $\mathrm{INa}^{+} p$ rather than a generalized block of total $\mathrm{INa}^{+}$. Some methodologic differences might account for this apparent discrepancy, such as the cell type used: we recorded pyramidal neurons whose native channel subunit composition is preserved. Furthermore, the persistent fraction of $\mathrm{INa}^{+}$was not investigated in the previous work.

Compelling evidence supports a central role of $\mathrm{Ca}^{2+}$ channels in epileptogenesis. The prolonged membrane depolarization during PDS causes a sustained activation of HVA currents, allowing a significant intracellular $\mathrm{Ca}^{2+}$ influx $(12,14)$. Moreover, an anomalous assembly of HVA $\mathrm{Ca}^{2+}$ channel subunits, as has been shown in a variety of mutant rodent models, such as the epileptic-lethargic mouse (43), appears of critical importance in the mechanisms underlying epilepsy. Hence a central mechanism by which AEDs modulate intrinsic neuronal excitability is represented by the inhibition of $\mathrm{Ca}^{2+}$ currents. Different AEDs have been shown to modulate HVA currents, such as levetiracetam (14), felbamate (FBM), and gabapentin (GBP). Among these, FBM and GBP have been found to interact selectively with L-type HVA channels $(44,45)$. Our results suggest that in cortical neurons, propofol selectively targets dihydropyridine-sensitive $\mathrm{Ca}^{2+}$ currents, which represent nearly $25 \%$ of the whole $\mathrm{Ca}^{2+}$ conductance. Indeed, the inhibitory action on $\mathrm{Ca}^{2+}$ currents by 
A

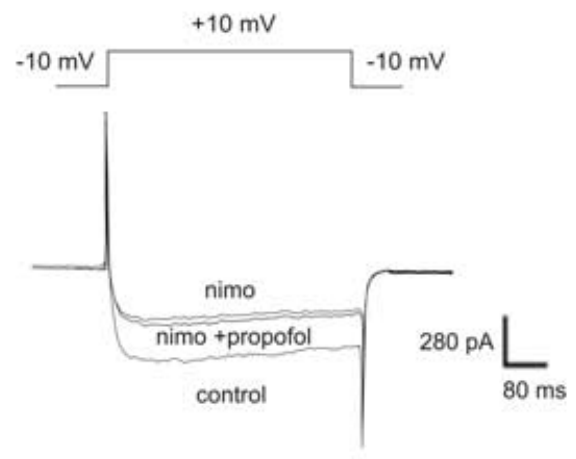

C
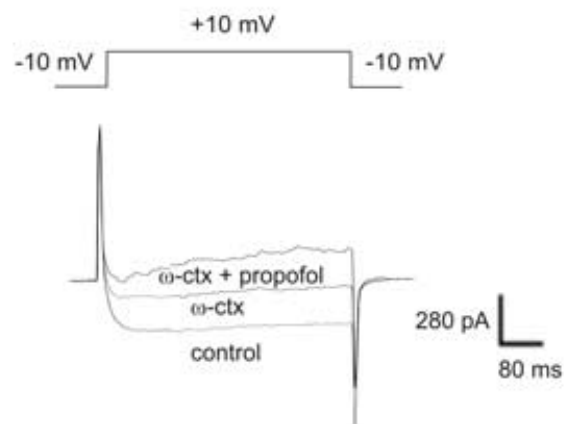

E

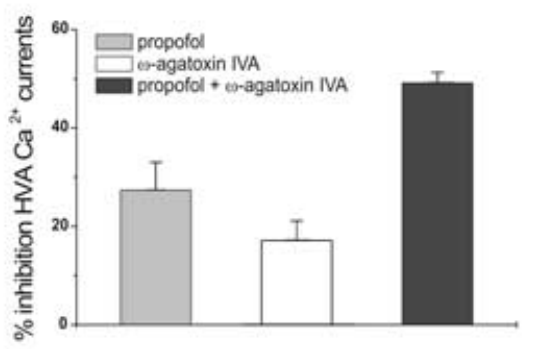

B

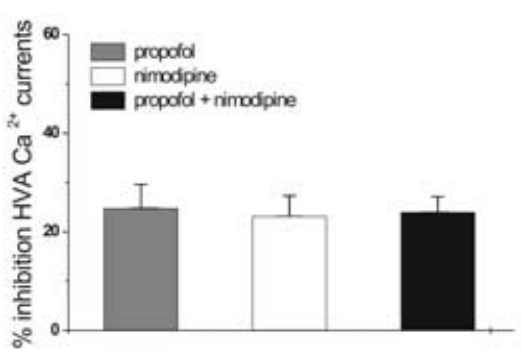

D

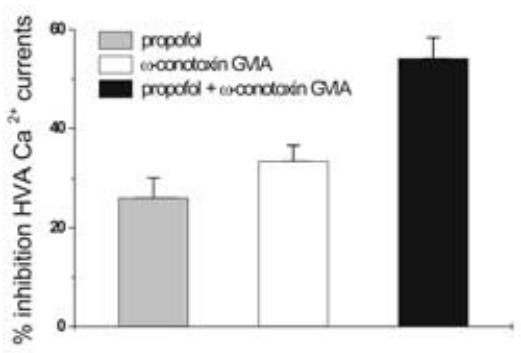

$\mathrm{F}$

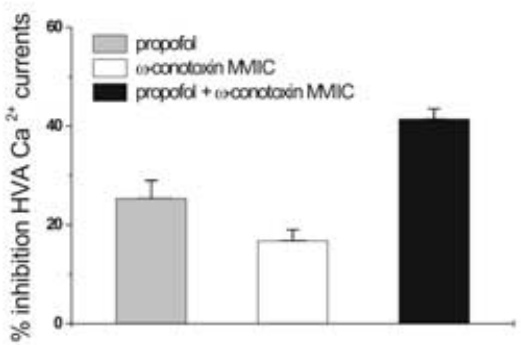

FIG. 8. Selective blockade of L-type high-voltage activated (HVA) $\mathrm{Ca}^{2+}$ currents by propofol. A: Barium currents were activated by step pulses ranging from $-10 \mathrm{mV}$ to $+10 \mathrm{mV}$. The selective $\mathrm{L}$-type $\mathrm{Ca}^{2+}$ channel blocker nimodipine (nimo, $5 \mu \mathrm{M}$ ) largely suppressed the total $\mathrm{Ca}^{2+}$ current. In the presence of nimodipine, the inhibitory effect of saturating concentrations of propofol was occluded. B: Cumulative plot showing the occlusion by nimodipine on the inhibitory action of propofol. C: One $\mu M \omega$-conotoxin GVIA ( $\omega$-ctx) significantly reduced the total $\mathrm{Ca}^{2+}$ current. However, with addition of propofol to the solution, an additive effect was obtained. D: The plot shows how the inhibition produced by $100 \mu \mathrm{M}$ propofol was further enhanced by $\omega$-conotoxin GVIA. E, F: The inhibitory effect of saturating doses of propofol was not occluded either by $20 \mathrm{nM} \omega$-agatoxin IVA or by $100 \mathrm{nM} \omega$-conotoxin MVIIC, selective blockers of P-type and Q-type HVA currents, respectively. The plots shown in $\mathbf{B}, \mathbf{D}, \mathbf{E}$, and $\mathbf{F}$ represent the mean \pm SEM of at least six independent recordings for each HVA antagonist.

saturating concentrations of propofol was selectively occluded by nimodipine, whereas perfusion with other channel subtype blockers resulted in an additive inhibition. These results are in accordance with previous observations obtained in spinal and supraoptic neurons $(46,47)$. The modulatory action on L-type channels might well explain the decrease in PDS duration reported in the present work. Indeed, PDSs are plateau potentials, with a prominent component mediated by activation of L-type $\mathrm{Ca}^{2+}$ conductances (46). Similarly, the blockade of L-type HVA channels might well account for the inhibition of AHP after each PDS, because AHP is mediated largely by $\mathrm{Ca}^{2+}$ activated potassium currents $(48,49)$. At present, a pos- sible effect on different types of potassium currents (50) cannot be ruled out, and future work is required to address this issue.

\section{Clinical implications}

The convergence of the $\mathrm{EC}_{50}$ values for the inhibitory effects of propofol both on PDS duration and HVA channels indeed suggests that $\mathrm{Ca}^{2+}$ current blockade might represent a primary mechanism for the antiepileptic action of this drug. However, the issue of clinically relevant concentrations for intravenous anesthetics is complex, mainly because of the difficulty of establishing steady-state free concentrations of anesthetic drugs in the brain $(6,51)$. Hence 
caution should be paid when determining a direct correlation between propofol concentrations tested in vitro and clinically effective plasma levels. Indeed, several pharmacokinetic parameters may account for such discrepancy: this may be particularly relevant with respect to propofol, a highly lipophilic drug, with a significant binding to plasma proteins (52). In our study, we found that propofol selectively blocked $\mathrm{INa}^{+} p$ with an $\mathrm{IC}_{50}$ of $\sim 4 \mu M$, which is a rather low concentration, in accordance with previously calculated therapeutic plasma levels. Moreover, propofol has been reported to reduce peak $\mathrm{Na}^{+}$currents in Chinese hamster ovary cells transfected with rat brain IIa $\mathrm{Na}^{+}$ channels with an $\mathrm{IC}_{50}$ of $10 \mu M$ (22). An in vivo study performed in rats reported that clinically relevant doses of propofol during anesthesia are $>10 \mu M(53)$.

Thus it may be conceivable to assume that low drug concentrations, such as those found to inhibit $\mathrm{INa}^{+} p$, may possibly participate to its antiepileptic efficacy observed in the treatment of refractory status epilepticus $(17,18)$.

Acknowledgment: We thank Mr. M. Tolu and Mr. F. Lavaroni for their excellent technical support. This work was supported by grants from: MIUR-CNR to A.P., P.C., and G.B (Cofin), Ministero Salute to A.P.; MIUR to A.P. (FIRB and Cofin).

\section{REFERENCES}

1. MacIver MB. General anesthetic action on transmission at glutamate and GABA synapses. In: Biebuyck JF, Lynch CIII, Maze M, eds. Anesthesia: biological foundations. New York: Lippincott-Raven, 1997:277-86.

2. Todorovic SM, Perez-Reyes E, Lingle CJ. Anticonvulsants but not general anesthetics have differential blocking effects on different T-type current variants. Mol Pharmacol 2000;58:98-108.

3. Ragsdale DS, Avoli M. Sodium channels as molecular targets for antiepileptic drugs. Brain Res Brain Res Rev 1998;26:16-28.

4. Calabresi P, Centonze D, Marfia GA, et al. An in vitro electrophysiological study on the effects of phenytoin, lamotrigine and gabapentin on striatal neurons. Br J Pharmacol 1999;126:689-96.

5. Calabresi P, Cupini LM, Centonze D, et al. Antiepileptic drugs as a possible neuroprotective strategy in brain ischemia. Ann Neurol 2003;53:693-702.

6. Yamakura T, Bertaccini E, Trudell JR, et al. Anesthetics and ion channels: molecular models and sites of action. Annu Rev Pharmacol Toxicol 2001;41:23-51.

7. Lingamaneni R, Hemmings HCJr. Differential interaction of anaesthetics and antiepileptic drugs with neuronal $\mathrm{Na}+$ channels, $\mathrm{Ca}^{2+}$ channels, and GABA(A) receptors. Br J Anaesth 2003;90:199-211.

8. Segal MM, Douglas AF. Late sodium channel openings underlying epileptiform activity are preferentially diminished by the anticonvulsant phenytoin. J Neurophysiol 1997;77:3021-34.

9. Taverna S, Mantegazza M, Franceschetti S, et al. Violate selectively reduces the persistent fraction of $\mathrm{Na}+$ current in neocortical neurons. Epilepsy Res 1998;32:304-8.

10. Taverna S, Sancini G, Mantegazza M, et al. Inhibition of transient and persistent $\mathrm{Na}+$ current fractions by the new anticonvulsant topiramate. J Pharmacol Exp Ther 1999;288:960-8.

11. Spadoni F, Hainsworth AH, Mercuri NB, et al. Lamotrigine derivatives and riluzole inhibit INa,P in cortical neurons. Neuroreport 2002; $13: 1167-70$

12. Badea T, Goldberg J, Mao B, Yuste R. Calcium imaging of epileptiform events with single-cell resolution. J Neurobiol 2001;48:21527.

13. Avanzini G, Franceschetti S. Cellular biology of epileptogenesis. Lancet Neurol 2003;2:33-42.
14. Pisani A, Bonsi P, Martella $\mathrm{G}$, et al. Intracellular calcium rise in epileptiform activity: modulation by levetiracetam and lamotrigine. Epilepsia 2004;45:1-10.

15. Modica PA, Tempelhoff R, White PF. Pro- and anticonvulsant effects of anesthetics (Part I). Anesth Analg 1990;70:303-15.

16. Fulton B, Sorkin EM. Propofol: an overview of its pharmacology and a review of its clinical efficacy in intensive care sedation. Drugs 1995;50:636-57.

17. Brown LA, Levin GM. Role of propofol in refractory status epilepticus. Ann Pharmacother 1998;32:1053-9.

18. Hirsch NP, Smith M. Review of the evidence for the use of propofol in the management of status epilepticus. J Neurol 2003;250: 1241 .

19. Hara M, Kai Y, Ikemoto Y. Propofol activates $\mathrm{GABA}_{\mathrm{A}}$ receptorchloride ionophore complex in dissociated hippocampal pyramidal neurons of the rat. Anesthesiology 1993;79:781-8.

20. Orser BA, Wang LY, Pennefather PS, et al. Propofol modulates activation and desensitization of $\mathrm{GABA}_{\mathrm{A}}$ receptors in cultured murine hippocampal neurons. J Neurosci 1994;14:7747-60.

21. Bieda MC, MacIver MB. A major role for tonic $\mathrm{GABA}_{\mathrm{A}}$ conductances in anesthetic suppression of intrinsic neuronal excitability. $J$ Neurophysiol 2004;92:1658-67.

22. Rehberg B, Duch DS. Suppression of central nervous system sodium channels by propofol. Anesthesiology 1999;91:512-20.

23. Connors B. Initiation of synchronized neuronal bursting in neocortex. Nature 1984;310:685-7.

24. Matsumoto H, Marsan CA. Cortical cellular phenomena in experimental epilepsy: ictal manifestations. Exp Neurol 1964;25:305-26.

25. Prince DA. Physiological mechanisms of focal epileptogenesis. Epilepsia 1985;26(suppl 1):S3-14.

26. Siniscalchi A, Calabresi P, Mercuri NB, et al. Epileptiform discharge induced by 4-aminopyridine in magnesium-free medium in neocortical neurons: physiological and pharmacological characterization. Neuroscience 1997;81:189-97.

27. Pisani A, Calabresi P, Tozzi A, et al. Early sodium elevations induced by combined oxygen and glucose deprivation in pyramidal cortical neurons. Eur J Neurosci 1998;10:3572-4.

28. Connors BW. Initiation of synchronized neuronal bursting in neocortex. Nature 1984;310:685-7.

29. Connors BW, Gutnick MJ. Intrinsic firing patterns of diverse neocortical neurons. Trends Neurol Sci 1990;13:99-104.

30. Pape HC. Queer current and pacemaker: the hyperpolarizationactivated cation current in neurons. Annu Rev Physiol 1996;58:299_ 327.

31. Schwindt P, O'Brien JA, Crill W. Quantitative analysis of firing properties of pyramidal neurons from layer 5 of rat sensorimotor cortex. J Neurophysiol 1997;77:2484-98.

32. Berger T, Larkum ME, Lüscher H-R. High Ih channel density in the distal apical dendrite of layer $\mathrm{V}$ pyramidal cells increases bidirectional attenuation of EPSPs. J Neurophysiol 2001;85:855-68.

33. Avanzini G, Franceschetti S. Cellular biology of epileptogenesis. Lancet Neurol 2003;2:33-42.

34. Zhang ZW. Maturation of layer V pyramidal neurons in the rat prefrontal cortex: intrinsic properties and synaptic function. $J \mathrm{Neu}$ rophysiol 2004;91:1171-82.

35. Ulrich D. Differential arithmetic of shunting inhibition for voltage and spike rate in neocortical pyramidal cells. Eur J Neurosci 2003;18:2159-65.

36. Franceschetti S, Guatteo E, Panzica F, et al. Ionic mechanisms underlying burst firing in pyramidal neurons: intracellular study in rat sensorimotor cortex. Brain Res 1995;696:127-39.

37. Crill WE. Persistent sodium current in mammalian central neurons. Annu Rev Physiol 1996;58:349-62.

38. Segal MM. Endogenous bursts underlie seizure-like activity in solitary excitatory hippocampal neurons in microcultures. J Neurophysiol 1994;72:1874-84.

39. Matsuki N, Quandt FN, Tan Eick RE, et al. Characterization of the block of sodium channels by phenytoin in mouse neuroblastoma cells. J Pharmacol Exp Ther 1984;228:523-30.

40. Willow M, Gonoi T, Catterall WA. Voltage clamp analysis of the inhibitory actions of diphenylhydantoin and carbamazepine on voltage-sensitive sodium channels in neuroblastoma cells. Mol Pharmacol 1985;27:549-58. 
41. Niespodziany I, Klitgaard H, Margineanu DG. Is the persistent sodium current a specific target of anti-absence drugs? Neuroreport 2004; 15:1049-52.

42. Frenkel C, Urban BW. Human brain sodium channels as one of the molecular target sites for the new intravenous anaesthetic propofol (2,6-diisopropylphenol). Eur J Pharmacol 1991;208:75-9.

43. McEnery MW, Vance CL, Begg CM, et al. Differential expression and association of calcium channel subunits in development and disease. J Bioenerg Biomembr 1998;30:409-18.

44. Stefani A, Spadoni F, Siniscalchi A, et al. Lamotrigine inhibits Ca2+ currents in cortical neurons: functional implications. Eur J Pharmacol 1996;307:113-6.

45. Stefani A, Spadoni F, Giacomini P, et al. The effects of gabapentin on different ligand- and voltage-gated currents in isolated cortical neurons. Epilepsy Res 2001;43:239-48.

46. Guertin PA, Hounsgaard J. Non-volatile general anaesthetics reduce spinal activity by suppressing plateau potentials. Neuroscience 1999;88:353-8.

47. Inoue Y, Shibuya I, Kabashima N, et al. The mechanism of in- hibitory actions of propofol on rat supraoptic neurons. Anesthesiology 1999;91:167-78.

48. Schwindt PC, Spain WJ, Crill WE. Calcium-dependent potassium currents in neurons from cat sensorimotor cortex. J Neurophysiol 1992;67:216-26.

49. Villalobos C, Shakkottai VG, Chandy KG, et al. SK $\mathrm{Ca}$ channels mediate the medium but not the slow calcium-activated afterhyperpolarization in cortical neurons. $J$ Neurosci 2004;24:3537-42.

50. Franceschetti $\mathrm{S}$, Lavazza $\mathrm{T}$, Curia $\mathrm{G}$, et al. $\mathrm{Na}^{+}$-activated $\mathrm{K}^{+}$current contributes to postexcitatory hyperpolarization in neocortical intrinsically bursting neurons. J Neurophysiol 2003;89:2101-11.

51. Franks NP, Lieb WR. Molecular and cellular mechanisms of general anaesthesia. Nature 1994;367:607-14.

52. Servin F, Desmonts JM, Haberer JP, et al. Pharmacodynamics and protein binding of propofol in patients with cirrhosis. Anesthesiology 1988;69:887-91.

53. Shyr MH, Tsai TH, Tan PP, et al. Concentration and regional distribution of propofol in brain and spinal cord during propofol anesthesia in the rat. Neurosci Lett 1995;184:212-5. 